\title{
Coupled Interannual Variability of Wind and Sea Surface Temperature in the Caribbean Sea and the Gulf of Mexico
}

\author{
GEIDY RODRIGUEZ-VERA \\ Posgrado en Ciencias de la Tierra, Centro de Ciencias de la Atmósfera, Universidad Nacional Autónoma de México, \\ Mexico City, Mexico \\ ROSARIO ROMERO-CENTENO \\ Centro de Ciencias de la Atmósfera, Universidad Nacional Autónoma de México, Mexico City, Mexico \\ CHRISTOPHER L. CASTRO \\ Department of Hydrology and Atmospheric Sciences, The University of Arizona, Tucson, Arizona \\ Víctor MENDOZa CASTRO \\ Centro de Ciencias de la Atmósfera, Universidad Nacional Autónoma de México, Mexico City, Mexico
}

(Manuscript received 31 August 2018, in final form 11 April 2019)

\begin{abstract}
This work describes dominant patterns of coupled interannual variability of the 10-m wind and sea surface temperature in the Caribbean Sea and the Gulf of Mexico (CS\&GM) during the period 1982-2016. Using a canonical correlation analysis (CCA) between the monthly mean anomalies of these fields, four coupled variability modes are identified: the dipole (March-April), transition (May-June), interocean (JulyOctober), and meridional-wind (November-February) modes. Results show that El Niño-Southern Oscillation (ENSO) influences almost all the CS\&GM coupled modes, except the transition mode, and that the North Atlantic Oscillation (NAO) in February has a strong negative correlation with the dipole and transition modes. The antisymmetric relationships found between the dipole mode and the NAO and ENSO indices confirm previous evidence about the competing remote forcings of both teleconnection patterns on the tropical North Atlantic variability. Precipitation in the CS and adjacent oceanic and land areas is sensitive to the wind-SST coupled variability modes from June to October. These modes seem to be strongly related to the interannual variability of the midsummer drought and the meridional migration of the intertropical convergence zone in the eastern Pacific. These findings may eventually lead to improving seasonal predictability in the CS\&GM and surrounding land areas.
\end{abstract}

\section{Introduction}

The Caribbean Sea and the Gulf of Mexico (CS\&GM) constitutes one of the most interesting tropical regions in terms of synoptic-scale climate features and their intraseasonal and interannual variability. The southwestern portion of the semipermanent North Atlantic

Supplemental information related to this paper is available at the Journals Online website: https://doi.org/10.1175/JCLI-D-18 0573.s1.

Corresponding author: Rosario Romero-Centeno, rosario@ atmosfera.unam.mx subtropical high (NASH) drives easterly surface trade winds in the region. Where these easterly winds are locally strongest, in the vicinity of $15^{\circ} \mathrm{N}, 75^{\circ} \mathrm{W}$, the Caribbean low-level jet (CLLJ) is defined (Amador 1998; Amador and Magaña 1999; Wang 2007; Whyte et al. 2008). The strength of the CLLJ varies seasonally in relation to the position and intensity of the NASH, particularly during the summer months (RomeroCenteno et al. 2003; Wang 2007; Cook and Vizy 2010).

The CS\&GM region is located within the Western Hemisphere warm pool (WHWP), where sea surface temperature (SST) climatologically exceeds $28.5^{\circ} \mathrm{C}$ during late summer (Wang and Enfield 2001; Wang 2004). The WHWP facilitates convective precipitation 
in the Caribbean islands, Central America (CA) and southern Mexico (Mestas-Nuñez et al. 2007; Wang 2007; Durán-Quesada et al. 2010). On the Pacific side of CA and southern Mexico, there are two periods of maximum precipitation during the wet season that occur in May-June and September-October. There is a relative minimum of convective activity and rainfall during JulyAugust that is commonly referred to as the midsummer drought or canícula (MSD; Magaña et al. 1999; Amador et al. 2006, 2016). A similar double peak structure in the annual cycle of precipitation also occurs in the Caribbean basin (e.g., Taylor et al. 2002; Gamble et al. 2008; Curtis and Gamble 2008).

The strength of air-sea coupling in the tropical North Atlantic (TNA) has been assessed in previous studies, either by computation of coupled modes of atmospheric circulation and SST (e.g., Servain and Legler 1986; Enfield and Alfaro 1999; Frankignoul and Kestenare 2005; Handoh et al. 2006; Chang and Oey 2013; Maldonado et al. 2017), or by relating regional climate to the remote influence of El Niño-Southern Oscillation (ENSO; e.g., Curtis and Hastenrath 1995; Enfield and Mayer 1997; Klein et al. 1999; Ruiz-Barradas et al. 2000; Alexander and Scott 2002; Huang et al. 2002; Handoh et al. 2006). ENSO has a clear relationship with SST variability in the TNA (Melice and Servain 2003), and this connection is most apparent during the subsequent spring of an ENSO event that reaches its mature phase in winter (Enfield and Mayer 1997; Giannini et al. 2000; Wang 2004). TNA SST and winds are also influenced by the North Atlantic Oscillation (NAO; e.g., Sutton et al. 2000; George and Saunders 2001; Czaja et al. 2002).

Much of the interannual variability in CS\& GM seems to be associated with remote climate forcing emanating from other parts of the world (e.g., Curtis and Hastenrath 1995; Enfield and Mayer 1997; Giannini et al. 2000; George and Saunders 2001; Czaja et al. 2002). There is evidence that the CLLJ varies in phase with NAO and it has an opposite relationship with ENSO in winter and summer (Wang 2007; Amador 2008). According to Giannini et al. (2001), though ENSO and NAO appear to be independent mechanisms that drive climate variability, their influence overlaps in the TNA. Likewise, SST anomalies (SSTA) and the extension of the WHWP are influenced by ENSO (Wang and Enfield 2001), and recent research has pointed out the potential influence of the WHWP in remote regions (Park et al. 2018).

In the CS\&GM there is ample evidence of strong ocean-atmosphere coupling on seasonal and interannual time scales (e.g., Enfield and Alfaro 1999; Wang 2007; Cook and Vizy 2010; Amador et al. 2010; Chang and Oey 2013). For example, during July, the relative maximum of the CLLJ coincides with the occurrence of the MSD and with a decrease in tropical cyclogenesis in the CS. Coupled ocean-atmosphere processes have been proposed to explain this behavior: an increase in divergent moisture flow in the Caribbean associated with the intensification of the CLLJ (Wang 2007), and high vertical wind shear in July acting against the organization of deep convection (Amador et al. 2010).

Using a singular value decomposition analysis, Enfield and Alfaro (1999) suggest that precipitation anomalies over the CS and CA are related to SSTA in the Atlantic and Pacific oceans. Giannini et al. (2000) employed a canonical correlation analysis (CCA) technique to investigate the relationships between rainfall, sea level pressure, and SST with respect to the Caribbean-Central America interannual climate variability. The conclusions of previous studies indicate strong relationships between SST, atmospheric circulation and precipitation (Alfaro 2007; Maldonado and Alfaro 2010, 2011; Fallas López and Alfaro 2012; Maldonado et al. 2013, 2016b, 2017).

In this study, we use a CCA method to explore the seasonal varying nature of the wind-SST coupling in the CS\&GM. We address the following research questions: How do wind-SST coupled modes vary through the course of the year? Are these coupled modes being modulated by some large-scale ocean-atmosphere patterns such as ENSO and NAO? Finally, we illustrate how the regional air-sea coupling impacts precipitation in the CS\&GM and surrounding land areas, especially during summer and the MSD months.

The paper is organized as follows. Sections 2 and 3 describe the data and methods used in this study, respectively. Section 4 includes the results on the windSST coupled modes (section 4a), their relationships with NAO and ENSO variability (section $4 \mathrm{~b}$ ), and the precipitation response to this coupling (section 4c). The conclusions are given in section 5 .

\section{Data}

\section{a. CFSR winds}

Zonal and meridional components of $10-\mathrm{m}$ winds are from the Climate Forecast System Reanalysis (CFSR; Saha et al. 2010, 2014). The CFSR dataset has a $0.5^{\circ}$ spatial resolution and a 6-h temporal resolution. The relatively long-time extent of CFSR makes it suitable for studying interannual climate variability. Our study period covers from 1982 to 2016.

\section{b. OISST}

NOAA Optimum Interpolation SST (OISST; Reynolds et al. 2007) is a daily dataset with a $0.25^{\circ}$ spatial resolution, which incorporates data from the 
Advanced Very High Resolution Radiometer (AVHRR) satellite sensors and in situ data from ships and buoys. This SST product includes a large-scale adjustment of satellite biases with respect to the in situ data. To perform statistical computations with the CFSR and OISST datasets, SST data are regridded to $0.5^{\circ} \times 0.5^{\circ}$ resolution within the area limited by $9^{\circ}-31^{\circ} \mathrm{N}$ and $100^{\circ}-60^{\circ} \mathrm{W}$. This domain defines our study region and includes the CS\&GM.

\section{c. CHIRPS and ERA-Interim precipitation}

Precipitation data comes from the Climate Hazards Group Infrared Precipitation with Station database (CHIRPS; Funk et al. 2015). This is a quasi-global $\left(50^{\circ} \mathrm{N}-50^{\circ} \mathrm{S}\right)$ gridded rainfall dataset, starting in 1981 to near-present day. CHIRPS incorporates satellite imagery with available in situ station data to create a $0.05^{\circ}$ spatial resolution precipitation product. For the analyses, we selected a domain wider than the study region, between $0^{\circ}$ and $40^{\circ} \mathrm{N}$ and between $110^{\circ}$ and $50^{\circ} \mathrm{W}$, which includes continental areas around CS\&GM, the northeastern tropical Pacific, and the western tropical Atlantic. CHIRPS has demonstrated good performance within Latin America in comparison with ground-truth precipitation gauge measurements, for example, in Colombia and Venezuela (Verdin et al. 2016; Paredes-Trejo et al. 2016). Furthermore, Perdigón-Morales et al. (2018) showed that CHIRPS reproduces reasonably well the principal climatological features of Mexican precipitation, including the MSD.

The CHIRPS dataset provides enhanced spatial resolution relative to other available global precipitation products. This is important for regions like CA, where precipitation is heavily influenced by orography (e.g., Waylen et al. 1996; Maldonado et al. 2016b). We also use the Monthly Means of Daily Forecast Accumulations product from the ERA-Interim project (model forecast step $0-12 \mathrm{~h}$ and $\sim 0.75^{\circ}$ resolution grid; Dee et al. 2011) interpolated on a $0.125^{\circ}$ grid as another precipitation dataset to compare with CHIRPS.

\section{d. NAO and ENSO indexes}

The NAO index (NAOI) and the oceanic Niño index (ONI) are used as indicators of the evolution and variability of NAO and ENSO, respectively. NAOI also serves as a proxy for the variability of the NASH. Both indexes are available from the NOAA's Climate Prediction Center website. To determine the NAO phases, values of the monthly NAOI above (below) the second (first) tercile for the period 1950-2016 are defined as positive (negative), consistent with Lee et al. (2008).

\section{Methods}

\section{a. Surface winds and SST anomalies}

All time series were filtered using three-month running means centered on each calendar month at each grid point. Linear trends were subtracted from the data. Then, climatological means and standardized anomalies were computed based on the study period (1982-2016).

\section{b. Canonical correlation analysis}

Before considering coupled patterns of variability between wind and SST, we first apply empirical orthogonal function (EOF) analysis independently to both fields. Since wind is a vector field, the EOF analysis includes the zonal and meridional wind components in the same matrix. This technique is referred to as simultaneous principal component analysis, or combined EOF (CEOF; von Storch and Zwiers 2002; Wilks 2006; Navarra and Simoncini 2010). Then, CCA (Barnett and Preisendorfer 1987; Bretherton et al. 1992) is performed to explore the statistical coupling between wind and SST interannual fluctuations over the CS\&GM for each calendar month. Singular value decomposition is applied to the covariance matrix of a subset of the leading EOFs of the two fields to maximize the correlation between their expansion coefficients. The input data for the analysis are truncated to reduce the high sampling variability of CCA modes (see Wallace et al. 1992; von Storch and Zwiers 2002; Wilks 2006). Though CCA identifies the optimal pairs of linear combinations of two datasets by maximizing covariance, it does not establish a physical causality.

In CCA analysis, the number of retained EOFs together should explain $\sim 70 \%$ of the variance of each field (Bretherton et al. 1992; von Storch and Zwiers 2002), so as to reduce spatial noise and biases. Considering this criterion, our input data consist of the first six CEOFs of wind and the first five EOFs of SST. Using the normalized expansion coefficients of the retained modes, a $6 \times 5$ covariance matrix is computed. Singular values of this matrix are the canonical correlations $r$ and indicate the strength of statistical coupling. Canonical correlation vectors $(\mathrm{CCV})$ are obtained by projecting the matrix of truncated data onto the singular vectors.

Heterogeneous correlation maps (HCMs) show the spatial anomaly patterns of these modes. These maps are generated by the regression of the input truncated data of one field onto the CCV of the other (Bretherton et al. 1992). Because the CCVs are normalized, these maps are given in the units of the represented field. HCMs indicate how well the pattern of anomalies in one field can be described by the canonical correlation of the other field and vice versa (Wallace et al. 1992; 
von Storch and Zwiers 2002). Another useful metric is the squared covariance fraction (SCF) explained by each mode, computed based on the squared singular values (Bretherton et al. 1992). The SCF indicates the percentage of the squared covariance that is explained by a pair of coupled patterns.

The fraction of the variance of SST and both wind components that is explained locally by each CCA mode is computed by the squared correlations between the time series of anomalies of each field and the respective CCV (von Storch and Zwiers 2002). The spatial average of this magnitude yields the percentage of variance (PV) of zonal wind, meridional wind, and SST that is accounted for by each CCA mode (see Wallace et al. 1992).

Following the algorithm described above, the coupled patterns of the interannual variability of SST and wind are obtained for each of the 12 calendar months, using the filtered series as defined in section 3a. In this work, we focus on the leading CCA mode of each month, which represents a pair of spatial anomaly patterns of the fields involved (HCMs) and their associated time series (CCVs). This combination explains the highest fraction of the covariance between both fields throughout the year, and we refer it as the "main coupled signal" in the spatial and temporal domains considered in this study.

\section{c. CCA index and correlations with teleconnection patterns}

The CCA index (CCAI) is defined as the arithmetic mean of the pairs of CCVs for wind and SST for each CCA pattern (similar to Handoh et al. 2006). Since these pairs of vectors are highly correlated, the CCAIs are considered as a very accurate representation of the interannual variability of the coupled modes. Lagged linear correlations between CCAIs and the ONI and NAOI are computed to identify the linkages of the main coupled ocean-atmosphere variability modes with the interannual fluctuations of ENSO and NAO. The significance of all correlations is estimated at the $95 \%$ confidence level (Wilks 2006).

\section{d. Precipitation variability associated with the coupling}

To capture possible connections of coupled signals with the variability of summer precipitation over CS\&GM and adjacent areas, we also found the corresponding precipitation anomaly patterns $\left(P_{\mathrm{CCAI}}\right)$. This is performed by the projection of the time series of precipitation anomalies $\left(P_{\text {anom }}\right)$ onto the monthly CCAIs [Eq. (1)]. To estimate the percentage of the climatological precipitation $\left(\mathrm{Pct}_{P}\right)$ that is represented by those anomalies, we apply Eq. (2). Then, the sign of the correlation between the monthly precipitation anomalies and the corresponding CCAI is mapped, yielding a map that shows anomalously high or low precipitation in reference to climatology.

$$
\begin{aligned}
P_{\mathrm{CCAI}} & =\frac{P_{\mathrm{anom}} \times \mathrm{CCAI}}{N}, \text { and } \\
\operatorname{Pct}_{P} & =\left(\frac{P_{\mathrm{CCAI}} \times \operatorname{Std}_{P}}{\bar{P}}\right) \times 100,
\end{aligned}
$$

where CCAI, $N, \bar{P}$, and $\operatorname{Std}_{P}$ refer to the monthly CCAI, time series length, and precipitation mean and standard deviation for each grid point, respectively.

\section{Results and discussion}

\section{a. Annual variability in the study region}

Figure 1 shows the climatological means of SST and 10-m winds in the CS\&GM for the 35 years from 1982 to 2016. Prevailing easterly winds are observed throughout the year. High SSTs $\left(\sim 28^{\circ}-29^{\circ} \mathrm{C}\right)$ persist during summer and fall in CS\& GM, associated with the development of the WHWP. A meridional SST gradient is apparent in winter and spring above $\sim 20^{\circ} \mathrm{N}$ (Figs. 1a,b); in this area, SST decreases with increasing latitude in part because of the meridional gradient of insolation. The highest SSTs $\left(>29^{\circ} \mathrm{C}\right)$ within the $\mathrm{GM}$ occur in summer, while in the CS they occur during fall. The amplitude of the SST annual cycle is larger in the GM than the rest of the domain because it is a semienclosed sea, with a strong influence on seasonal temperature changes over the continent (Zavala-Hidalgo et al. 2002).

Two regions that exhibit local SST minima are the Gulfs of Tehuantepec and Papagayo in the eastern tropical Pacific (see location in Fig. 1a). Offshore winds crossing the corresponding mountainous isthmuses favor entrainment of subsurface cold water, vertical mixing, and surface evaporation (Stumpf 1975; Barton et al. 1993; Liang et al. 2009). This oceanic response is more apparent during boreal winter (Fig. 1a), when trades and seasonal northerlies are very strong (Legeckis 1988). The intrusion in the GM of cold air masses and high pressure systems from midlatitude during winter increases the meridional sea level pressure gradient between the GM and Gulf of Tehuantepec, favoring the intensification of these winds (Romero-Centeno et al. 2007). In the subsequent analysis of the anomalies in the CS\&GM, reference will be made to these monthly features of winds and SST.

\section{b. Variability of the coupled fields}

The basic statistics regarding the first two dominant or leading CCA modes for all calendar months are 

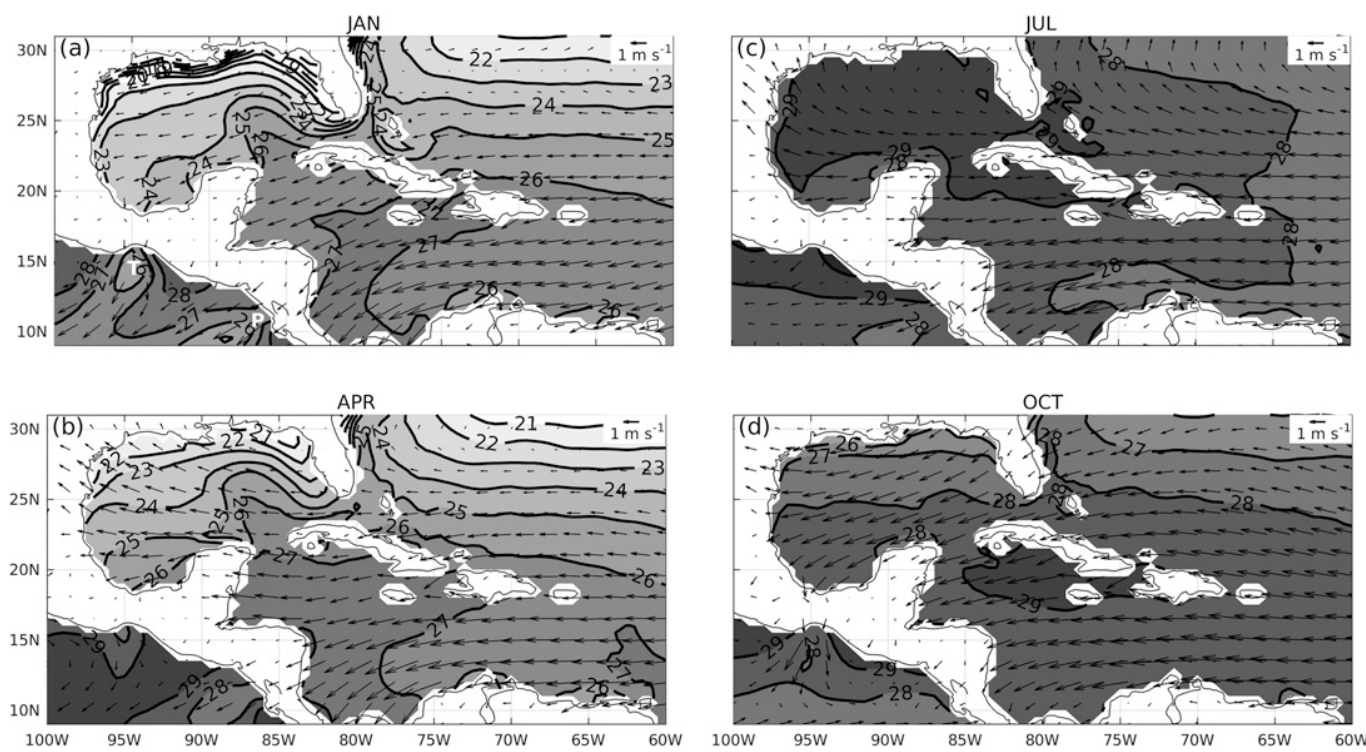

FIG. 1. Climatological means of SST $\left({ }^{\circ} \mathrm{C}\right.$; contours $)$ and $10-\mathrm{m}$ winds $\left(\mathrm{m} \mathrm{s}^{-1}\right.$; vectors) over the $1982-2016$ period, based on three-month running averages centered on: (a) January, (b) April, (c) July, and (d) October. In (a), the white letters T and P locate the Gulfs of Tehuantepec and Papagayo, respectively.

presented in Table 1, beginning in March and ending in February. The canonical correlation coefficients for the leading CCA modes $\left(r_{1}\right)$ show values between 0.87 and 0.96 , indicating that the wind-SST coupling in the study region is very strong. These monthly CCA modes account for just over one-third of the covariance of the input data, as expressed by $\mathrm{SCF}_{1}$. The values of the second canonical correlation coefficients $\left(r_{2}\right)$ range from 0.69 to 0.85 . These second modes also account for considerable covariance $\left(\mathrm{SCF}_{2}\right)$. While not discounting the rest of the coupled CCA modes, this work is mainly focused on the leading modes. The leading modes explain the highest fraction of the covariance between both fields throughout the year, and therefore represent the principal coupled signal.

TABLE 1 . Monthly canonical correlation coefficients $(r)$ and SCF (percentage) for the first and second CCA modes.

\begin{tabular}{lcccc}
\hline Months & $r_{1}$ & $\mathrm{SCF}_{1}$ & $r_{2}$ & $\mathrm{SCF}_{2}$ \\
\hline Mar & 0.89 & 35 & 0.81 & 31 \\
Apr & 0.88 & 31 & 0.69 & 24 \\
May & 0.93 & 33 & 0.81 & 29 \\
Jun & 0.92 & 30 & 0.85 & 27 \\
Jul & 0.92 & 32 & 0.74 & 26 \\
Aug & 0.96 & 33 & 0.69 & 24 \\
Sep & 0.91 & 34 & 0.69 & 26 \\
Oct & 0.92 & 34 & 0.73 & 27 \\
Nov & 0.96 & 30 & 0.76 & 24 \\
Dec & 0.94 & 35 & 0.84 & 31 \\
Jan & 0.92 & 34 & 0.79 & 29 \\
Feb & 0.87 & 31 & 0.77 & 27 \\
\hline
\end{tabular}

Even though $r_{1}$ and $\mathrm{SCF}_{1}$ do not exhibit sharp contrasts throughout the year, the PV accounted for by the monthly leading CCA modes indicates a marked seasonal variation (Table 2). The PV of SST ranges from $20 \%$ to $35 \%$, reaching maximum values in February, March and April, and minimum values in May, June, and October. With respect to the wind field, the PV suggests that on the interannual time scale the zonal (meridional) component is more relevant for the wind-SST coupling from March to October (November to February).

The monthly HCMs of the leading coupled spatial patterns in the CS\&GM are shown in Fig. 2. For the most part, the spatial anomaly pattern does not substantially change from month to month. An important

TABLE 2. PV of the SST and the zonal $(U)$ and meridional $(V)$ wind components that is accounted for by the leading CCA mode of each month.

\begin{tabular}{lccc}
\hline \hline Months & SST & $U$ & $V$ \\
\hline Mar & 32 & 43 & 14 \\
Apr & 31 & 23 & 15 \\
May & 22 & 18 & 11 \\
Jun & 22 & 26 & 16 \\
Jul & 24 & 32 & 22 \\
Aug & 24 & 34 & 25 \\
Sep & 24 & 31 & 21 \\
Oct & 20 & 25 & 12 \\
Nov & 28 & 17 & 26 \\
Dec & 25 & 13 & 35 \\
Jan & 29 & 11 & 34 \\
Feb & 35 & 11 & 30 \\
\hline
\end{tabular}



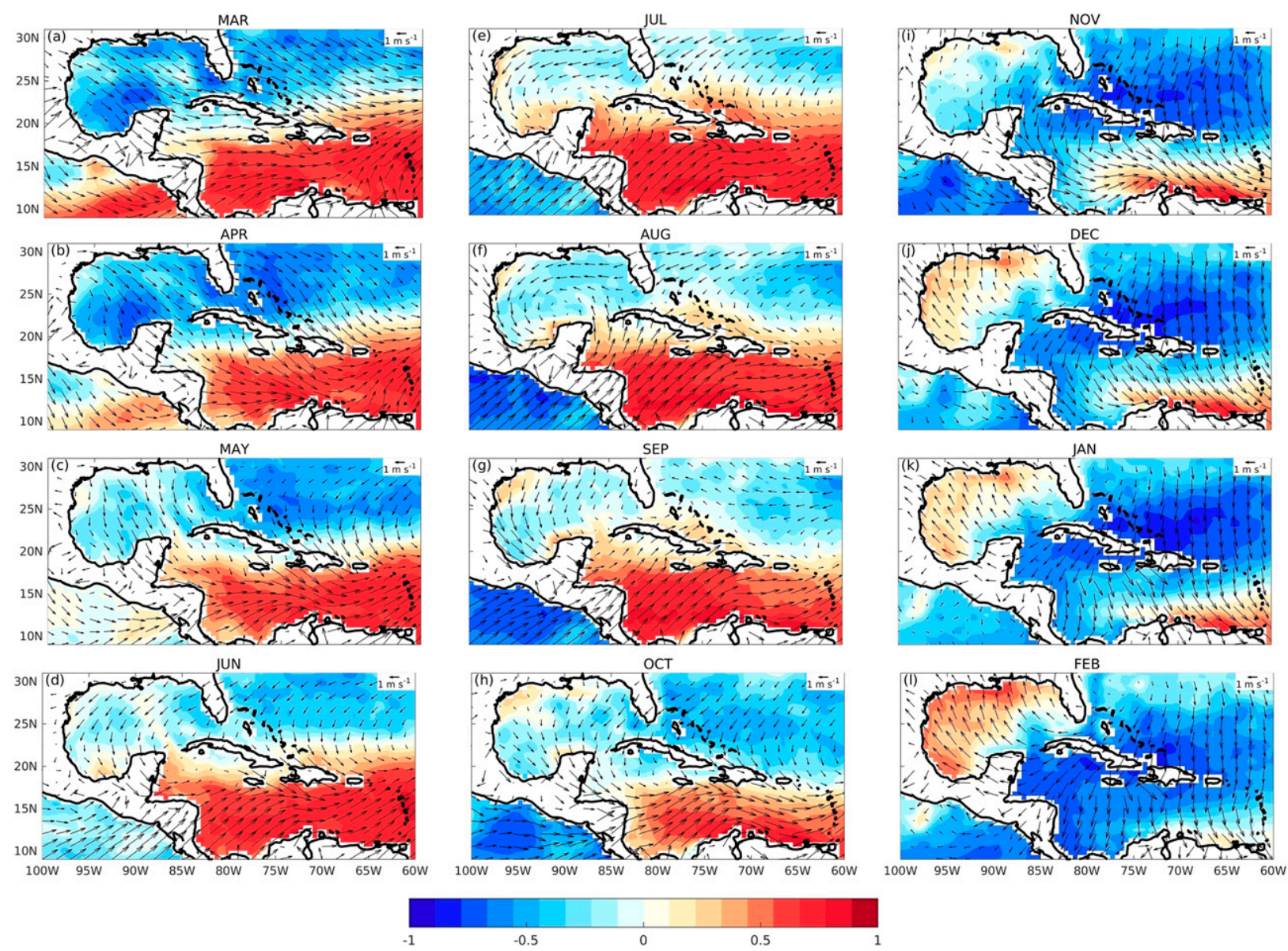

FIG. 2. Heterogeneous correlation maps of the leading monthly coupled modes. Color shading and arrows indicate the SST $\left({ }^{\circ} \mathrm{C}\right)$ and wind $\left(\mathrm{m} \mathrm{s}^{-1}\right)$ standardized anomalies regressed onto the CCVs for wind and SST, respectively. Months begin in (a) March and end in (1) February, according to the main text.

exception is the change from February to March, which have clearly different spatial features (Figs. 2a,1). By inspecting the second pair of coupled patterns obtained in the CCAs, the leading mode in February appears as the second mode in March and vice versa (shown in the online supplemental material). In other words, both modes emerge as the first two CCA modes in February and March, but one of them is accounting for more covariance in each month. The negative phases would then be opposite to those shown in Fig. 2. Henceforth, unless explicitly mentioned otherwise, our descriptions will refer to the positive phase.

Although there are similarities in the HCMs from March to October and from November to February, these structures evolve during the course of an annual cycle. The seasonal dependency in the CS\&GM oceanatmosphere coupling is shown by the monthly spatial configuration of the local explained variance (LEV) for both wind components and SST that is accounted for by the leading CCA modes (Fig. 3). Figure 3 shows the LEV for March, May, August, and December, which are representative months of four different anomaly configurations. Despite the fact that the variance is a positive magnitude, the LEV maps are presented with the correlation sign at each grid point, in order to be consistent with the spatial patterns. When observing the spatial characteristics of the CCA modes (Fig. 2) and that of the LEV (Fig. 3), we classify four distinct configurations:

\section{1) Dipole MODE: MARCH-APRIL}

The dipole structure of the SSTA, positive in the CS and negative in the GM and the rest of the domain (Figs. 2a,b), is fundamentally influenced by zonal wind anomalies (Fig. 3a). This dipole extends to the Pacific Ocean adjacent to CA, mainly in March and diminishes in April. Northwesterly wind anomalies over the GM bring cold and dry air from the continent, which increase 

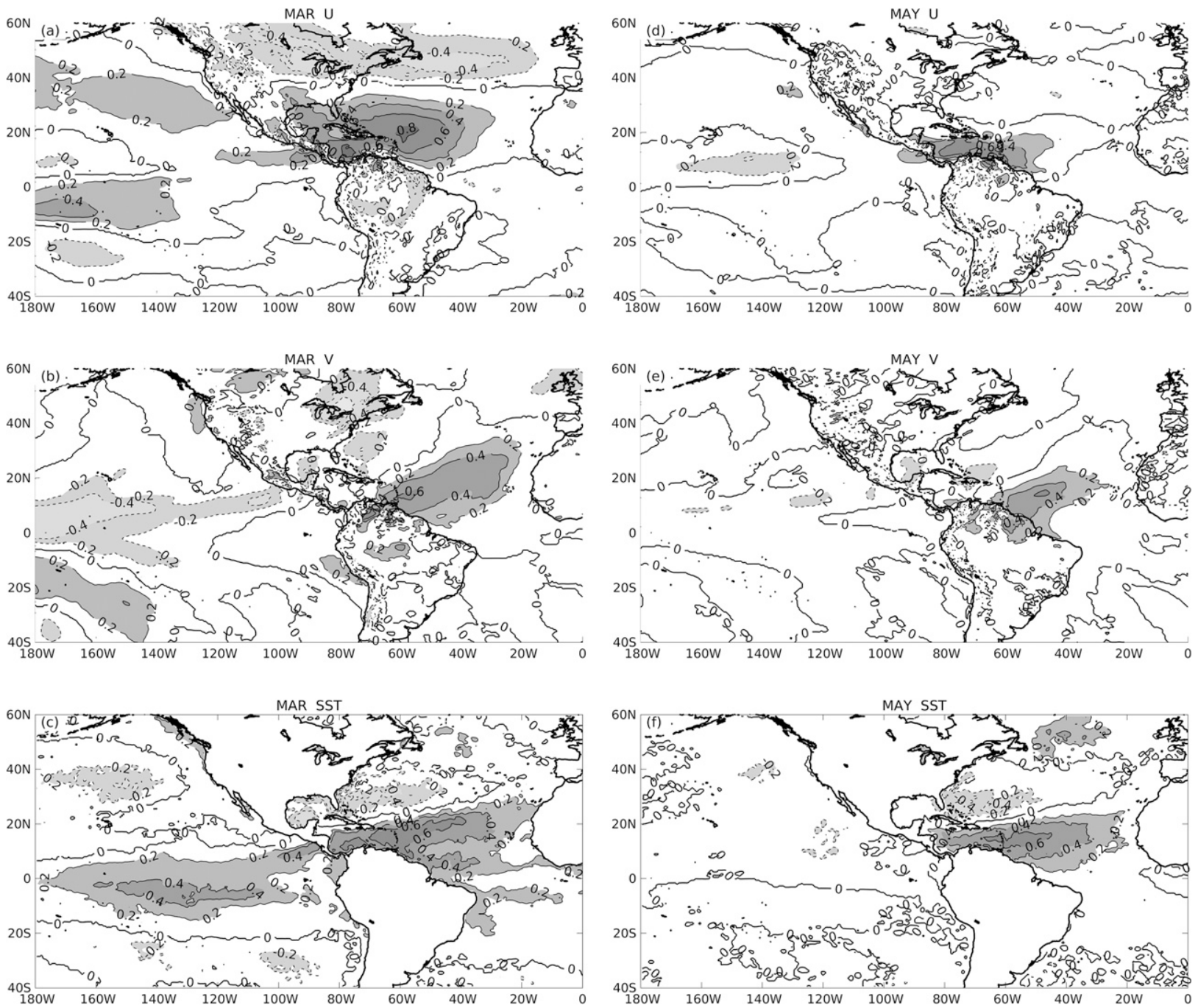

FIG. 3. Local variance of the zonal wind $U$, meridional wind $V$, and SST accounted for by the leading CCVs of (a)-(c) March, (d)(f) May, (g)-(i) August, and (j)-(l) December, respectively. Positive (darker colors, continuous lines) and negative (lighter colors, dashed lines) values correspond to the sign of the correlation. Contour interval is 0.2 , and values within the range from -0.2 to 0.2 are left blank.

evaporation and latent heat flux and produce below normal SSTs. Over the CS, wind anomalies in the opposite direction to the climatological trades lead to a decrease in wind speed, reducing evaporation and raising the Caribbean SST (Enfield and Mayer 1997; Klein et al. 1999). These results are consistent with the springtime wind anomalies and the associated SST dipole described by Muñoz and Enfield (2011).

This antisymmetric configuration of SSTA has a strong resemblance with the meridional dipole pattern of the intra-Americas seas, which has been identified in several studies that occurs after a warm phase of ENSO, preceding an anomalous WHWP event, and also linked to the NAO tripole pattern (Alexander and Scott 2002; Enfield et al. 2006; Deser et al. 2010; Muñoz et al. 2010; Liu et al. 2015). Here, a similar distribution of SSTA has emerged in combination with the interannual variability of simultaneous surface winds as the leading coupled mode in March-April.

\section{2) Transition MOdE: MAY-JUnE}

The dipole structure of SSTA is weaker in May-June compared with previous months, as the signal almost disappears in the GM and no longer crosses into the eastern Pacific (Figs. 2c,d). This transition mode is dominated mainly by zonal wind anomalies, as illustrated in the LEV maps (Figs. 3d,e). The HCMs show most of the wind-SST covariability in the southern Caribbean, where persistent westerly anomalies are coupled with warmer SSTs. These low-level circulation anomalies associated with sea surface warming can be interpreted using Gill's (1980) model. This mechanism 

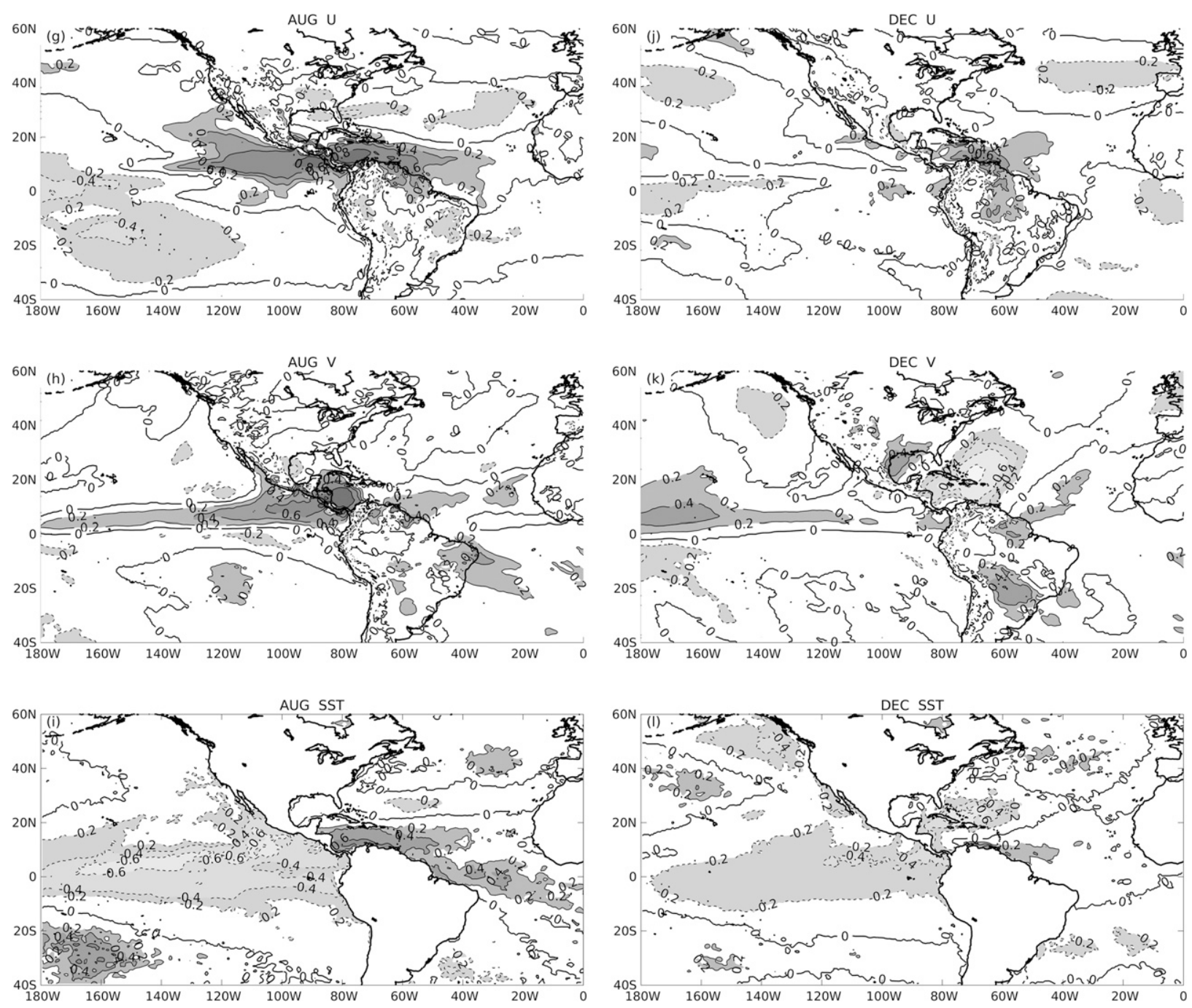

FIG. 3. (Continued)

was first pointed out by Magaña et al. (1999) to explain the MSD evolution and was also commented in Maldonado et al. (2017) saying that it favors rainy conditions during May-June in the Pacific slope of CA. A weak CLLJ has been associated with positive SSTA and increased rainfall in the Caribbean (e.g., Wang et al. 2008; Cook and Vizy 2010; Rauscher et al. 2011).

\section{3) INTEROCEAN MOdE: JULY-OCTOBER}

From July to October, positive SSTA in the Caribbean persist and are opposite to those in the eastern Pacific. This interocean mode is strongly associated with southwesterly wind anomalies (Figs. 2e-h). The PV and LEV of the zonal and meridional winds increase with respect to the transition mode (Table 2 and Figs. 3g,h), but in October this pattern weakens significantly. Similar Pacific-Atlantic asymmetry in the SSTA has been linked with summer precipitation variability over the CS
(Taylor et al. 2002; Spence et al. 2004) and CA (Enfield and Alfaro 1999; Alexander and Scott 2002; Alfaro 2007; Maldonado and Alfaro 2010; Maldonado et al. 2013) and has been observed during ENSO events. The implications of this coupled mode for the regional climate will be further examined in section $4 \mathrm{~d}$.

\section{4) Meridional-Wind MOde: November- FEBRUARY}

Unlike the previous modes, the pattern observed during the winter months is dominated by the meridional-wind variability (Fig. 3k). In fact, the PV of the meridional component is maximum from November to February (Table 2), as was mentioned before. The spatial configurations reveal northerly wind anomalies coupled with colder SSTs in the CS and the TNA (Figs. 2i-1). At the same time, southeasterly wind anomalies arise together with warmer SSTs in the GM, 


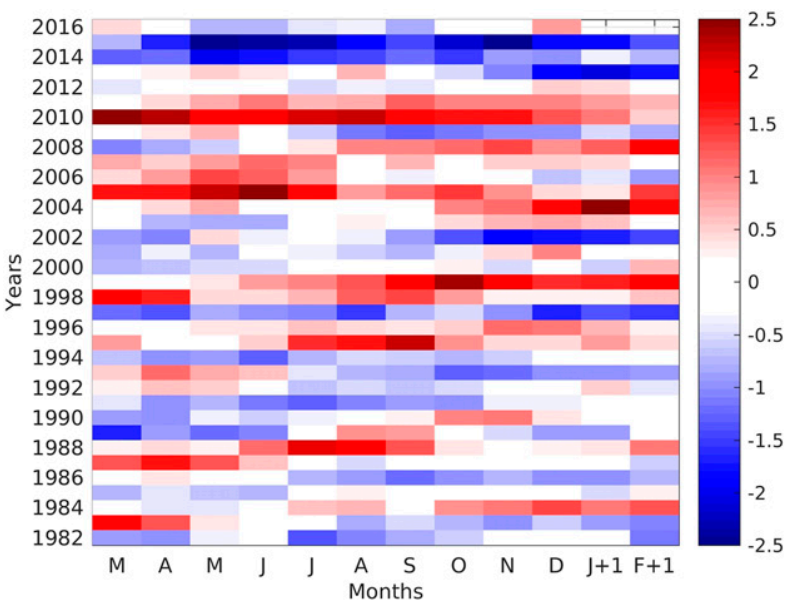

FIG. 4. CCA index from March of the year indicated in the vertical axis to February of the next year $(+1)$ for the period 1982-2016.

mainly from December to February. The meridionalwind mode may be related with the interannual variability of extratropical-latitude cold airmass intrusions and the frequency of northerly winds (Legeckis 1988; Zárate-Hernández 2013).

Along the northern coast of Venezuela, from November to January, there are warmer SSTs associated with northwesterly anomalies, favoring downwelling and weakening coastal upwelling in that area (RuedaRoa and Muller-Karger 2013). This result is consistent with Chang and Oey (2013), who pointed out the strong physical coupling between trade winds and the ocean waters along the coast of Venezuela.

The temporal component of each monthly CCA mode is illustrated in Fig. 4 through its respective CCAI. From left to right this graph starts with the CCAI of March and ends with the CCAI of February of the next year. The CCAIs exhibit considerable interannual fluctuations, alternating between positive and negative values that may persist for several months, as can be seen, for example, in 1997, 2005, 2010, and 2015 (Fig. 4). There is a high correlation between the CCAIs, even for nonconsecutive months.

The LEV maps suggest that the interocean(Figs. $3 g-i$ ) and meridional-wind (Figs. 3j-1) modes are closely connected with the variability of the eastern Pacific and with ENSO; while the transition mode seems to be more linked to the TNA variability (Figs. 3d-f). Additionally, the influence of the Pacific and tropical Atlantic might be superimposed on the coupled processes of the CS\&GM, possibly in the dipole mode (Figs. 3a-c). Consequently, the probable relationship of this coupled wind-SST variability with ENSO and NAO is examined next.

\section{c. Teleconnections}

We analyze the possible remote forcing from ENSO and NAO over the coupled ocean-atmosphere variability modes defined in section $4 \mathrm{~b}$. The CCAIs of the coupled modes identified within each anomalies configuration are averaged to have a time evolution representative of the dipole, transition, interocean, and meridional-wind modes during 1982-2016. Lagged correlation analysis between these averaged CCAIs and the monthly ONI and NAOI are shown in Fig. 5.

All modes, except the transition mode, show a strong relationship with the ENSO variability, represented by the ONI (Fig. 5a). The maximum significant correlations

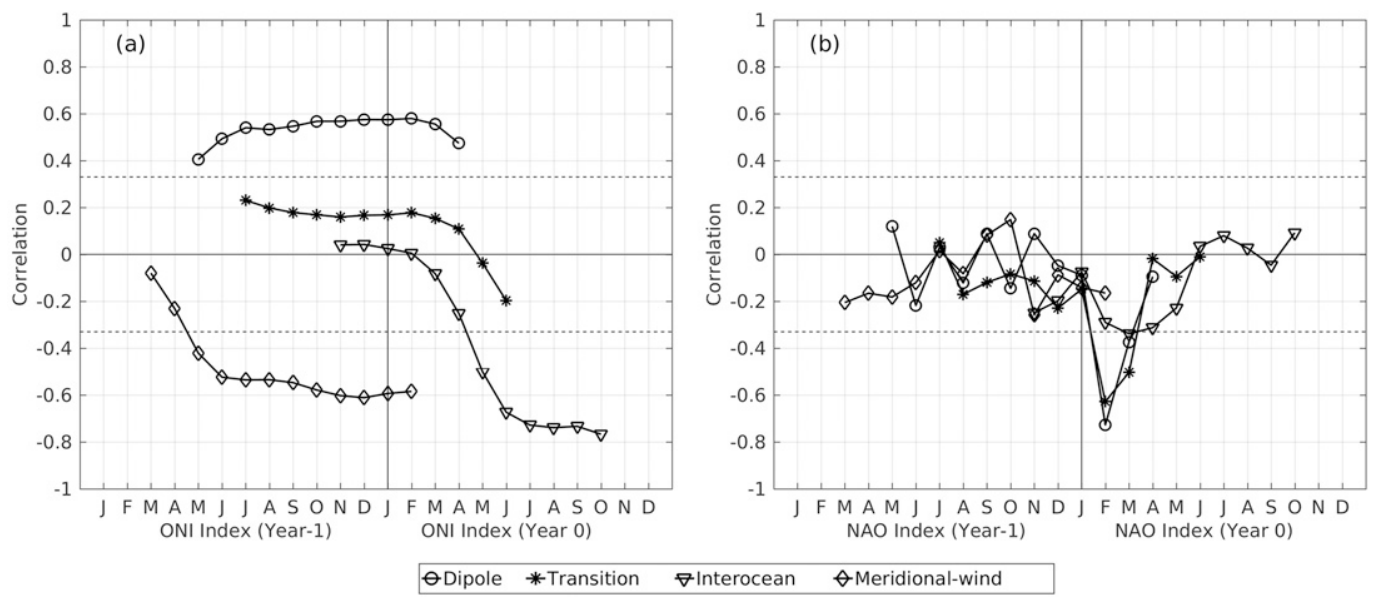

FIG. 5. Lagged correlations between the CCAIs of the four coupled modes and the monthly (a) ONI and (b) NAOI. Correlations were calculated starting from the last month that defines each mode, April for the dipole, June for the transition, October for the interocean, and February for the meridional wind, and continuing with the consecutive 12 monthly lags. The thick vertical line indicates the end of the previous year (Year-1) and the beginning of the current year (Year 0). Horizontal dashed lines indicate the $95 \%$ significant levels $(= \pm 0.33)$. 
(below -0.7) are between the interocean mode and the July-October ONI at zero lag; this mode is characteristic of the summer months, when ENSO events usually are in their initial stage. During summer and early fall, an ENSO warm signal favors the development of the negative phase of the interocean mode, represented by the opposite anomaly patterns to those shown in Figs. $2 \mathrm{e}-\mathrm{h}$. These patterns would indicate a strengthening of the easterlies and the CLLJ, which lead to cooler SSTs in the Caribbean. This finding is consistent with other studies (Wang et al. 2008; Amador et al. 2010; Martin and Schumacher 2011), which state that the CLLJ in the boreal summer increases (decreases) in response to warm (cold) ENSO events and, associated with these strong winds, the SST is anomalously cold.

The meridional-wind mode also shows significant negative correlations with the ONI, being around -0.6 from November to February, and maintains high values for several lags (Fig. 5a). This mode occurs during winter, coinciding with the mature stage of ENSO events; when a warm ENSO episode is developed, a negative phase of the meridional-wind mode tends to occur. This means that the pattern of wind anomalies would be opposite to that shown in Figs. $2 \mathrm{j}-1$, which would be representing the anomalous low pressure system that forms over the southeastern coast of the United States, one of the best-defined teleconnections during warm ENSO phases (Wallace and Gutzler 1981; Klein et al. 1999). Then, in conjunction with these wind anomalies, the CS and nearby Atlantic Ocean would experience anomalous warming and the GM would be cooling.

Previous studies have pointed out that during boreal winter and spring the Pacific-Atlantic teleconnection is strongest (Curtis and Hastenrath 1995; Enfield and Mayer 1997; Huang et al. 2002; Alexander and Scott 2002; Muñoz and Enfield 2011). As can be seen in Fig. 5a, positive lagged correlations between the dipole mode and ONI, around 0.6 at lags of $0-2$ months, confirm the importance of ENSO during the previous winter for the development of the wind-SST coupled response in the following spring. The SST anomaly dipole, which occurs in March-April, is quite consistent with the warming observed in the TNA during the spring after a mature warm ENSO. The weakening of the northerly trade winds leads to a reduction in sensible and latent heat losses in the region (e.g., Enfield and Mayer 1997; Alexander and Scott 2002; Muñoz et al. 2010).

Regarding the lagged correlations between CCAIs and NAOI, Fig. 5b shows a strong negative correlation between the dipole and transition modes and the winter NAOI, which accounts for roughly $35 \%-55 \%$ of the variance. During a negative NAO phase in winter, the positive phases of the dipole and transition modes (see

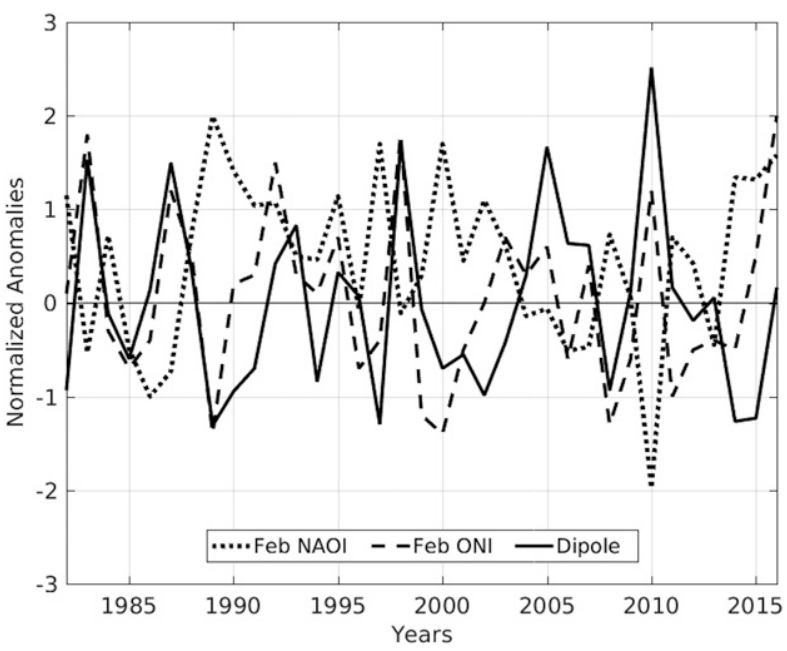

FIG. 6. Time series of the dipole mode and the ONI and NAOI for February.

Figs. 2a-d) tend to be enhanced in the following spring an early summer, consistent with the weakening of the trade winds in the TNA. The opposite occurs during a positive NAO phase. Some studies suggest that CLLJ fluctuations are in phase with NAO so that a strengthening of this oscillation coincides with an intense CLLJ and vice versa (Wang 2007; Maldonado et al. 2016a). Such wind anomalies in the Caribbean are, in turn, linked to SST variations. It is noteworthy that the behavior of the dipole mode associated with a negative NAO is similar to its response to a warm ENSO episode, as described before.

Two main points arise from this analysis. First, ENSO correlates with almost all the CS\&GM coupled modes, while NAO is associated only with the dipole and transition modes. Second, the dipole pattern can be modulated by both phenomena. The opposite sign of the ENSO and NAO correlations with the dipole mode would seem to indicate that their effects tend to counteract (reinforce) when they are in the same (opposite) phase. In this context, Fig. 6 provides the times series of the CCAI for the dipole mode and the ONI and NAOI for February (the central month of the quarterly average). The antisymmetric relationships with NAO and ENSO confirm previous evidence about the influence of remote forcing on TNA variability (Giannini et al. 2001; Czaja et al. 2002; Enfield et al. 2006).

We examined the phases of the dipole mode along the study period and those of NAO and ENSO observed during winter. The negative phase $(\mathrm{CCAI}<-0.5)$ of the dipole mode was present in 13 years, 10 of which coincided with a positive NAO and a neutral or negative ENSO (Table 3). Six of the eight years in which a positive $(\mathrm{CCAI}>0.5)$ dipole mode was present occurred 
TABLE 3. Phases of the February ONI and NAOI that preceded the positive or negative dipole mode events in March from 1982 to 2016. Years in which the dipole mode was in the neutral phase have been omitted because they do not show any relation with the NAO/ ENSO phases.

\begin{tabular}{|c|c|c|c|c|c|c|c|}
\hline Year & Feb ONI & Feb NAOI & Dipole mode & Year & Feb ONI & Feb NAOI & Dipole mode \\
\hline 1982 & 0 & $(+)$ & $(-)$ & 2000 & $(-)$ & $(+)$ & $(-)$ \\
\hline 1983 & $(+)$ & $(+)$ & $(+)$ & 2001 & $(-)$ & 0 & $(-)$ \\
\hline 1985 & $(-)$ & $(-)$ & $(-)$ & 2002 & 0 & $(+)$ & $(-)$ \\
\hline 1987 & $(+)$ & $(-)$ & $(+)$ & 2005 & $(+)$ & 0 & $(+)$ \\
\hline 1989 & $(-)$ & $(+)$ & $(-)$ & 2006 & $(-)$ & 0 & $(+)$ \\
\hline 1990 & 0 & $(+)$ & $(-)$ & 2007 & $(+)$ & 0 & $(+)$ \\
\hline 1991 & 0 & $(+)$ & $(-)$ & 2008 & $(-)$ & $(+)$ & $(-)$ \\
\hline 1993 & 0 & $(+)$ & $(+)$ & 2010 & $(+)$ & $(-)$ & $(+)$ \\
\hline 1994 & 0 & $(+)$ & $(-)$ & 2014 & 0 & $(+)$ & $(-)$ \\
\hline 1997 & 0 & $(+)$ & $(-)$ & 2015 & $(+)$ & $(+)$ & $(-)$ \\
\hline 1998 & $(+)$ & 0 & $(+)$ & & & & \\
\hline
\end{tabular}

following a warm ENSO event, without observing a predominant phase of NAO.

How is it that in some years the same positive or negative CCAI can emerge in spring and extend until the summer and fall, even though the sign of the significant correlation with ENSO (Fig. 5a) changes from the dipole to the interocean and meridional-wind modes? The evolution of ENSO indicates that the ending phase of a warm or cold event often coincides with the spring season, while the onset usually occurs during spring and/or summer (McGregor et al. 2012, and references there included). Therefore, a phase change of ENSO from spring to summer might allow the coupled anomaly response in the CS to maintain and strengthen, but it does not happen often.

An anomalously warm Pacific may not be sufficient for developing the dipole mode. The interaction with other processes that affect the variability of the TNA, like the NAO, may inhibit or reinforce this pattern of coupled anomalies. For example, the strongest positive phase of the dipole mode is observed in 2010 (Fig. 6), when an intense warm ENSO during the preceding winter coincided with the most negative NAO of the entire period. Afterward, the warm 2009-10 ENSO became cold in the early summer of 2010, which allowed the reinforcement and persistence of the wind-SST anomalies in the Caribbean during that year. Additionally, the rapid transition of a warm to a strong cold phase of the 2009-10 ENSO is unique; possible mechanisms for this fast transition have been suggested by Kim et al. (2011). The year 2010 was also very active in terms of named storms and hurricanes in the TNA.

\section{d. Precipitation response to ocean-atmosphere coupled variability}

The main wind-SST coupled anomalies at the interannual scale have implications for the climate, not only of the CS\&GM but also of other adjacent oceanic and land areas. To investigate this aspect, precipitation anomalies associated with the CCA modes are analyzed using the CHIRPS database. The general distribution and magnitude of the CHIRPS precipitation anomalies are consistent with those obtained from the ERAInterim data (not shown). The precipitation patterns associated with the leading coupled modes in winter and spring (meridional-wind and dipole), do not show a clear or strong response (not shown). Notably, the patterns of precipitation anomalies for these modes indicate a possible impact on the fluctuations of the meridional moisture flux into the southeastern United States and offshore.

Summer precipitation variability in the CS seems to be especially sensitive to the wind and SSTA. The percentages of increase or decrease in rainfall amounts represented by the regressed precipitation anomalies onto the leading CCAI from May to October, the wet season in the region, are shown in Fig. 7. Only grid points where precipitation anomalies are significantly correlated with the corresponding CCAIs are displayed, and wind anomaly patterns are superimposed. Warmer SSTs in the CS, favored by the transition and interocean modes, are an important source of heat and moisture, which, when trade winds are weaker, trigger deep convection and rainfall $20 \%-60 \%$ above average (Fig. 7). The higher intensity and spatial coverage of these anomalies are observed during July-August when its signal also becomes prominent in regions of the east and southeast of Mexico and western CA.

From a thermodynamic perspective, the precipitation response is consistent with the Clausius-Clapeyron equation. A small perturbation above the high climatological SSTs (around $28^{\circ} \mathrm{C}$ ) over the CS could cause significant changes in evaporation (Salby 1996). These conditions may favor more available moisture for 

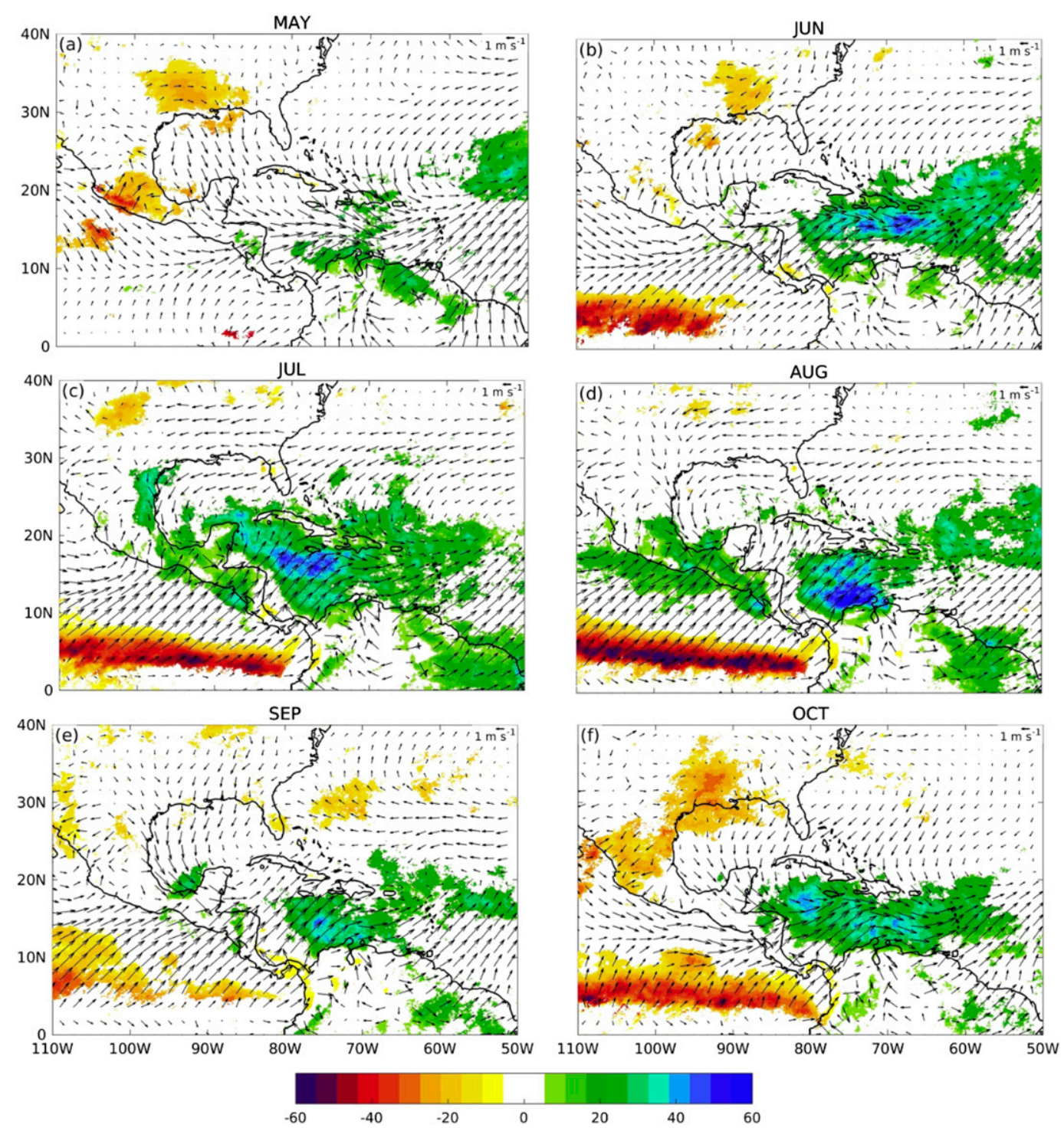

FIG. 7. Percentage of increase (positive values) or decrease (negative values) of precipitation with respect to its monthly climatological value and wind anomalies associated with the leading coupled modes from (a) May to (f) October.

precipitation. From a dynamic perspective, the strengthening or weakening of the easterlies modulates the summer precipitation (e.g., Taylor et al. 2002). Wind patterns from June to October (Figs. 7b-f) confirm that the CLLJ is inversely correlated with precipitation anomalies in the CS, particularly in July-August. This is the period when the MSD over the CS, southern Mexico, and the Pacific coast of CA occurs. The MSD is in phase with the seasonal fluctuations in the lower atmospheric circulation dominated by the trades and the CLLJ (Magaña and Caetano 2005; Wang 2007; Amador et al. 2010; Herrera et al. 2015).

The wind anomalies in the CS\&GM suggest a lowlevel circulation opposite to the subtropical dorsal that dominates over the region in summer because of the westward extension of the NASH (Romero-Centeno et al. 2007). From June to August, the center of this cyclonic anomaly experiences a zonal fluctuation, moving toward the west into the GM, but in SeptemberOctober it retreats again from the GM. According to Gill's model (Gill 1980), a cyclonic (anticyclonic) circulation anomaly at the surface would originate to the northwest of the heating source, analogous to the warm (cold) region in the CS (see Figs. 2c-h and Figs. 7). Therefore, the anomalies in the circulation imply a weaker influence of the anticyclonic ridge and a drop of the high pressure that usually develops in the GM. This favors less subsidence in the region and more favorable 
conditions for the ascent of moist air (e.g., Magaña et al. 1999; Maldonado et al. 2017). Curtis and Gamble (2008) describe that the MSD appears in early June in the eastern Caribbean and extends westward throughout the wet season with the seasonal expansion of the NASH. Thus, the coupled SST-wind patterns identified here might play an important role in the Caribbean MSD variability.

The precipitation anomalies associated with the interocean mode (Figs. 7c-f) confirm previous evidence that the Pacific-Atlantic SSTA modulate rainfall in CA during the MSD months and the late wet season (Alfaro 2007; Maldonado and Alfaro 2010, 2011; Maldonado et al. 2013, 2016b). Taylor et al. (2002) and Spence et al. (2004) suggest that opposite SSTA in the tropical Pacific and Atlantic basins influence Caribbean precipitation during the late wet season. The interocean mode seems to be linked to the spatial-temporal evolution of precipitation over CA, CS, and adjacent tropical Atlantic, as well as the Guyanas and northern Colombia and Venezuela.

Why is the effect on summer precipitation so apparent in July and August but not in September, even though the patterns of coupled variability are very similar to each other? As suggested above, this could depend on the base state, especially the monthly climatological mean of precipitation and its relationship with the windSST pattern. During July and August, stronger easterlies favor vertical homogenization of air masses, high vertical wind shear and relatively cooler SSTs in the CS, resulting in the suppression of organized deep convection (Wang 2007; Amador et al. 2010; Martin and Schumacher 2011). In contrast, during September, weaker easterlies and warmer SSTs coincide with the second precipitation maximum (Gamble et al. 2008; Maldonado 2015). Hence, the positive phase of the CCA leading modes in July-August-September will enhance precipitation in almost the entire $\mathrm{CS}$ and $\mathrm{CA}$, but the positive anomalies during July-August represent a greater difference with respect to the relative minimum of precipitation that occurs in the middle of summer.

A relatively small area stands out over the southwestern CS, the Caribbean side of CA and Panama, that does not show significant precipitation anomalies associated with the positive phase of the leading CCA modes (Fig. 7). This response is observed in regions where the MSD does not occur and, particularly, in Panama where the orientation of the topography is different; there the mountain range extends from east to west (Poveda et al. 2006), which may play a role in the interaction with the local circulation. This characteristic reinforces the idea that the influence of the coupled modes on the regional variability is observed mostly over the MSD region.
The southwesterly wind anomalies along the trade winds belt indicate a strengthening (weakening) of the southern (northern) trades and, together with the precipitation anomalies, suggest a possible impact on the eastern Pacific intertropical convergence zone (ITCZ; Philander et al. 1996; Amador et al. 2006) (Figs. 7c,d). The anomaly patterns for the positive phase of the coupled modes may reflect a northward displacement of the ITCZ, in agreement with the decrease in precipitation south of its mean position $\left(\sim 10^{\circ} \mathrm{N}\right)$, and an increase of the moisture transport toward the continent, in agreement with enhanced precipitation over CA and southern Mexico (Fig. 7). The deficit of precipitation south of the ITCZ mean position is consistent with the cold SSTA in the eastern Pacific suggested by the interocean mode (Figs. 2e-h), unlike the warming produced in the Caribbean basin. Hidalgo et al. (2015) proposed a dynamical mechanism that links the CLLJ and the meridional displacement of the eastern Pacific ITCZ with precipitation in CA. Our findings confirm that changes in the Caribbean and eastern tropical $\mathrm{Pa}$ cific circulation coupled with SSTA are linked with the variability of ITCZ position and precipitation during summer.

The inverse relationship of the interocean mode with ENSO, during warm phases of ENSO from July to October, indicates that anomalous precipitation patterns roughly opposite to those in Fig. 7 could be expected. In other words, the precipitation anomalies shown in Fig. 7 would tend to occur when a cold ENSO event occurs. This is consistent with Amador (2008), who found below (above) normal precipitation in the central CS and the Pacific side of CA, together with above (below) normal precipitation in the Caribbean, associated with warm (cold) ENSO episodes during summer.

With respect to Mexico, the impact of ENSO has been analyzed by Magaña et al. (2003) and Vázquez-Aguirre (2007). They point out that a warm (cold) ENSO in summer involves negative (zero or positive) precipitation anomalies over most of the country. According to these authors, the diminished precipitation observed during a warm ENSO is related to reinforced subsidence because of the ITCZ southward displacement and a smaller number of tropical cyclones in the intra-Americas seas.

\section{Conclusions}

The time-varying nature of the dominant wind-SST coupled modes in the CS\&GM region has been examined based on the space-time distribution of the windSST anomaly patterns represented by the monthly leading CCA modes. These modes of coupled variability 

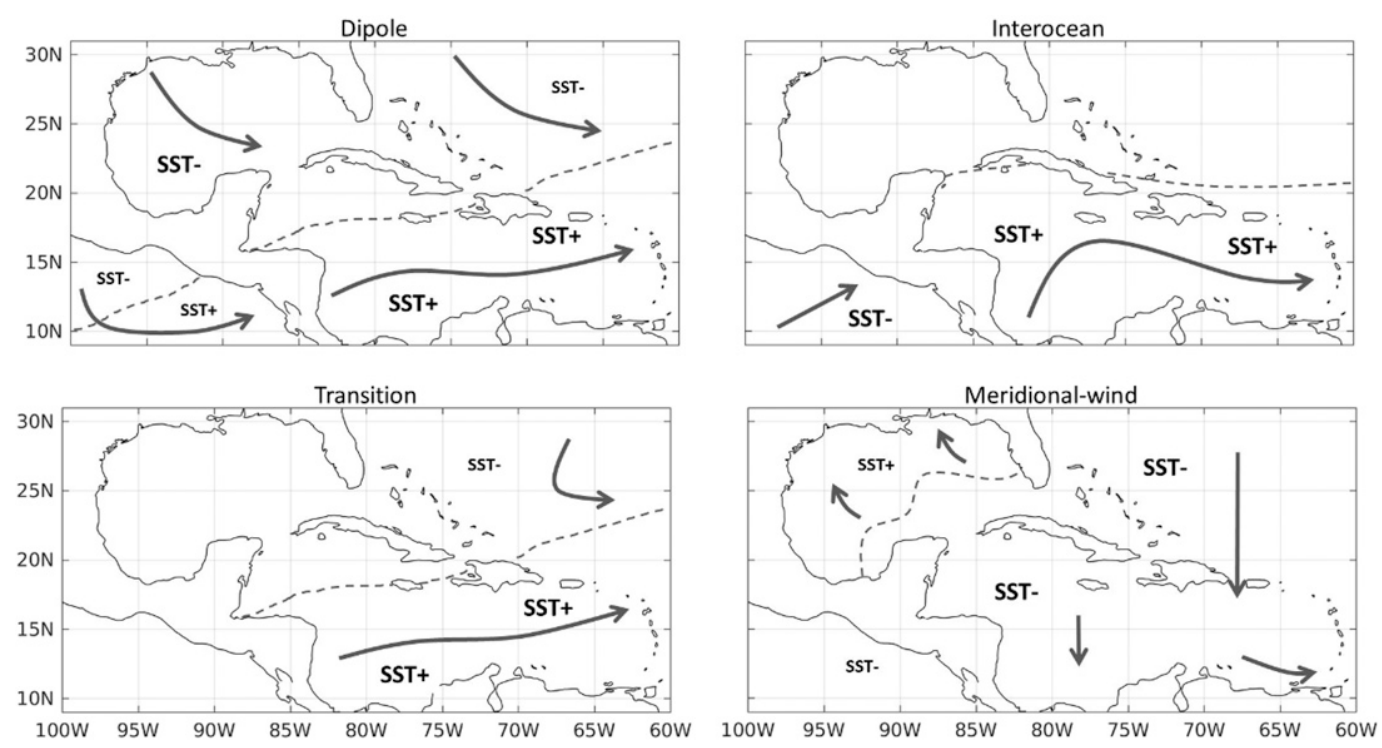

FIG. 8. Schemes of the four coupled wind-SST anomaly configurations: dipole, transition, interocean, and meridional-wind modes. SST $+(-)$ indicates positive (negative) SST anomalies, and the font size symbolizes the intensity of the anomaly. The dashed line divides regions with different signs of SST anomalies. Arrows indicate the direction of wind anomalies.

are classified by four configurations: the dipole mode (March-April), the transition mode (May-June), the interocean mode (July-October), and the meridionalwind mode (November-February). Figure 8 summarizes the main structures of these patterns, which are explained in detail in section $4 \mathrm{~b}$.

The correlation analyses show that ENSO influences the interannual variability of all except the transition mode. The dipole mode shows a positive correlation while the interocean and meridional-wind modes are correlated negatively with ENSO. Lagged correlations between the dipole mode and ONI confirm previous evidence on the importance of the occurrence of an ENSO event in the previous winter for the development of the coupled wind-SST response during the following spring (Alexander and Scott 2002; Wang 2004; Muñoz et al. 2010; Muñoz and Enfield 2011).

The dipole and transition modes show a strong negative correlation with the NAOI in winter. Consequently, the dipole mode can be modulated by both the ENSO and winter NAO. The negative phase of the dipole mode is more frequently associated with a positive NAO in the previous winter combined with a simultaneous cold or neutral ENSO, while its positive phase is mainly related to a warm ENSO, independently of the NAO phase.

The precipitation anomalies associated with the leading CCA modes from May to October indicate that the regional air-sea coupling modulates the wet season in the CS\&GM region, particularly the MSD. There are regions with precipitation anomalies about $20 \%-60 \%$ above/below its monthly climatology. In particular, high precipitation anomalies over eastern and southern regions of Mexico, western CA, and the eastern Pacific are shown in July and August. Around the location of the CLLJ, anomalous precipitation is inversely correlated with the intensity of the easterlies.

From June to August, an anomalous surface cyclonic circulation gradually emerges and moves westward; but in September-October, it retreats again from the GM. This west-east excursion of the cyclonic anomaly can be associated with variations of the NASH and, therefore, with fluctuations in subsidence. The center of the cyclonic circulation seems to follow the MSD region, so it is suggested that the coupled summer modes could regulate the bimodal seasonal cycle of precipitation in the region and the interannual variability of the MSD. The precipitation anomalies associated with the interocean mode confirm the essential role of the asymmetric Pacific-Atlantic SSTA on the CA rainfall variability during the MSD months and the late wet season (Alfaro 2007; Maldonado and Alfaro 2010, 2011; Maldonado et al. 2013, 2016b; Spence et al. 2004; Taylor et al. 2002).

Anomalies in the trade winds seem to have an impact on the meridional migration of the ITCZ in the eastern Pacific from June to October, as Hidalgo et al. (2015) suggest. The positive phase of the interocean mode could favor a northward displacement of the ITCZ and an intensification of moisture transport toward the continent. This is accompanied by enhanced 
precipitation over CA, southern Mexico and adjacent ocean, cold SSTA in the eastern Pacific, and warming in the CS. Therefore, the Caribbean and eastern Pacific low-level winds coupled with SSTA are linked with the variability of ITCZ position and regional precipitation during summer. The negative correlation found between the interocean mode and the ONI, suggests that a warm ENSO would tend to cause an anomalous southward displacement of the ITCZ (Hidalgo et al. 2015). This may be in correspondence with drier conditions over susceptible continental regions and the CS, and more rainfall over the ocean far from the American coasts.

An interesting question that arises from this work is whether the predictive skill of the coupled modes increases when the NAO and ENSO variability is known, especially during spring. Many authors have pointed out that other processes might modulate the TNA interannual variability, such as the Pacific-North American pattern and the Atlantic multidecadal oscillation (e.g., Barnston and Livezey 1987; Enfield et al. 2001; Hurrell et al. 2003; Muñoz et al. 2010; Muller-Karger et al. 2015; Liu et al. 2015). These climate forcings would yield some potential predictability skills for these four modes several months in advance. Therefore, future studies should investigate the possible modulation of several large-scale processes, in addition to those studied here. To assess predictive ability, the analysis performed in this study could be repeated using retrospective reforecast data, for example, from the NCEP Climate Forecast System, version 2. This knowledge could give us more clues to improve the seasonal forecasting ability for the CS\&GM and nearby continental areas.

Acknowledgments. This research was supported by the Programa Nacional de Posgrados de Calidad of the Consejo Nacional de Ciencia y Tecnología of Mexico and CONACYT-SENER-Hidrocarburos Project 201441. We want to thank the anonymous reviewers who helped greatly improve the original version of this manuscript.

\section{REFERENCES}

Alexander, M., and J. Scott, 2002: The influence of ENSO on airsea interaction in the Atlantic. Geophys. Res. Lett., 29, 1701 , https://doi.org/10.1029/2001GL014347.

Alfaro, E. J., 2007: Uso del análisis de correlación canónica para la predicción de la precipitación pluvial en Centroamérica. Ing. Compet., 9, 33-48.

Amador, J. A., 1998: A climatic feature of the tropical Americas: The trade wind easterly jet. Top. Meteor. Oceanogr., 5, 1-13. , 2008: The Intra-Americas seas low-level jet. Ann. N. Y. Acad. Sci., 1146, 153-188, https://doi.org/10.1196/annals.1446.012.

- and V. Magaña, 1999: Dynamics of the low level jet over the Caribbean Sea. Third Conf. on Hurricanes and Tropical Meteorology, Dallas, TX, Amer. Meteor. Soc., 401-402.
—, E. J. Alfaro, O. G. Lizano, and V. O. Magaña, 2006: Atmospheric forcing of the eastern tropical Pacific: A review. Prog. Oceanogr., 69, 101-142, https://doi.org/10.1016/j.pocean.2006. 03.007 .

, — - E. R. Rivera and B. Calderón, 2010: Climatic features and their relationship with tropical cyclones over the IntraAmericas seas. Hurricanes and Climate Change, Vol. 2, J. B. Elsner et al., Eds., Springer, 149-173, https://doi.org/10.1007/ 978-90-481-9510-7_9.

, A. M. Durán-Quesada, E. R. Rivera, G. Mora, F. Sáenz, B. Calderón, and N. Mora, 2016: The easternmost tropical Pacific. Part II: Seasonal and intraseasonal modes of atmospheric variability. Rev. Biol. Trop., 64, S23-S57, https:// doi.org/10.15517/rbt.v64i1.23409.

Barnett, T. P., and R. Preisendorfer, 1987: Origins and levels of monthly and seasonal forecast skill for United States surface air temperatures determined by canonical correlation analysis. Mon. Wea. Rev., 115, 1825-1850, https://doi.org/10.1175/15200493(1987)115<1825:OALOMA > 2.0.CO;2.

Barnston, A. G., and R. E. Livezey, 1987: Classification, seasonality and persistence of low-frequency atmospheric circulation patterns. Mon. Wea. Rev., 115, 1083-1126, https://doi.org/ 10.1175/1520-0493(1987)115<1083:CSAPOL>2.0.CO;2.

Barton, E. D., and Coauthors, 1993: Supersquirt: Dynamics of the Gulf of Tehuantepec, Mexico. Oceanography, 6, 23-30, https:// doi.org/10.5670/oceanog.1993.19.

Bretherton, C. S., C. Smith, and J. M. Wallace, 1992: An intercomparison of methods for finding coupled patterns in climate data. J. Climate, 5, 541-560, https://doi.org/10.1175/ 1520-0442(1992)005<0541:AIOMFF > 2.0.CO;2.

Chang, Y. L., and L. Y. Oey, 2013: Coupled response of the trade wind, SST gradient, and SST in the Caribbean Sea, and the potential impact on Loop Current's interannual variability. J. Phys. Oceanogr., 43, 1325-1344, https://doi.org/10.1175/ JPO-D-12-0183.1.

Cook, K. H., and E. K. Vizy, 2010: Hydrodynamics of the Caribbean low-level jet and its relationship to precipitation. J. Climate, 23, 1477-1494, https://doi.org/10.1175/ 2009JCLI3210.1.

Curtis, S., and D. W. Gamble, 2008: Regional variations of the Caribbean mid-summer drought. Theor. Appl. Climatol., 94, 25-34, https://doi.org/10.1007/s00704-007-0342-0.

, and S. Hastenrath, 1995: Forcing of anomalous sea surface temperature evolution in the tropical Atlantic during Pacific warm events. J. Geophys. Res., 100, 15 835-15 847, https:// doi.org/10.1029/95JC01502.

Czaja, A., P. Van der Vaart, and J. Marshall, 2002: A diagnostic study of the role of remote forcing in tropical Atlantic variability. J. Climate, 15, 3280-3290, https://doi.org/10.1175/15200442(2002)015<3280:ADSOTR > 2.0.CO;2.

Dee, D. P., and Coauthors, 2011: The ERA-Interim reanalysis: Configuration and performance of the data assimilation system. Quart. J. Roy. Meteor. Soc., 137, 553-597, https://doi.org/ 10.1002/qj.828.

Deser, C., M. A. Alexander, S. P. Xie, and A. S. Phillips, 2010: Sea surface temperature variability: Patterns and mechanisms. Annu. Rev. Mar. Sci., 2, 115-143, https://doi.org/10.1146/ annurev-marine-120408-151453.

Durán-Quesada, A. M., L. Gimeno, J. A. Amador, and R. Nieto, 2010: Moisture sources for Central America: Identification of moisture sources using a Lagrangian analysis technique. J. Geophys. Res., 115, D05103, https://doi.org/10.1029/ 2009JD012455. 
Enfield, D. B., and D. A. Mayer, 1997: Tropical Atlantic sea surface temperature variability and its relation to El Niño-Southern Oscillation. J. Geophys. Res., 102, 929-945, https://doi.org/ 10.1029/96JC03296.

_ - and E. J. Alfaro, 1999: The dependence of Caribbean rainfall on the interaction of the tropical Atlantic and Pacific Oceans. J. Climate, 12, 2093-2103, https://doi.org/10.1175/15200442(1999)012<2093:TDOCRO > 2.0.CO;2.

— A. M. Mestas-Nuñez, and P. J. Trimble, 2001: The Atlantic multidecadal oscillation and its relation to rainfall and river flows in the continental US. Geophys. Res. Lett., 28, 20772080, https://doi.org/10.1029/2000GL012745.

—, S. K. Lee, and C. Wang, 2006: How are large western hemisphere warm pools formed? Prog. Oceanogr., 70, 346-365, https://doi.org/10.1016/j.pocean.2005.07.006.

Fallas López, B., and E. J. Alfaro, 2012: Uso de herramientas estadísticas para la predicción estacional del campo de precipitación en América Central como apoyo a los Foros Climáticos Regionales. 2: Análisis de Correlación Canónica. Rev. Climatol., 12, 93-105.

Frankignoul, C., and E. Kestenare, 2005: Air-sea interactions in the tropical Atlantic: A view based on lagged rotated maximum covariance analysis. J. Climate, 18, 3874-3890, https:// doi.org/10.1175/JCLI3498.1.

Funk, C., and Coauthors, 2015: The climate hazards infrared precipitation with stations-A new environmental record for monitoring extremes. Sci. Data, 2, 150066, https://doi.org/ 10.1038/sdata.2015.66.

Gamble, D. W., D. B. Parnell, and S. Curtis, 2008: Spatial variability of the Caribbean mid-summer drought and relation to north Atlantic high circulation. Int. J. Climatol., 28, 343-350, https://doi.org/10.1002/joc. 1600 .

George, S. E., and M. A. Saunders, 2001: North Atlantic Oscillation impact on tropical north Atlantic winter atmospheric variability. Geophys. Res. Lett., 28, 1015-1018, https://doi.org/ 10.1029/2000GL012449.

Giannini, A., Y. Kushnir, and M. A. Cane, 2000: Interannual variability of Caribbean rainfall, ENSO, and the Atlantic Ocean. J. Climate, 13, 297-311, https://doi.org/10.1175/1520-0442(2000) 013<0297:IVOCRE $>2.0$. CO;2.

—, M. A. Cane, and Y. Kushnir, 2001: Interdecadal changes in the ENSO teleconnection to the Caribbean region and the North Atlantic Oscillation. J. Climate, 14, 2867-2879, https:// doi.org/10.1175/1520-0442(2001)014<2867:ICITET>2.0.CO;2.

Gill, A., 1980: Some simple solutions for heat-induced tropical circulation. Quart. J. Roy. Meteor. Soc., 106, 447-462, https:// doi.org/10.1002/qj.49710644905.

Handoh, I. C., A. J. Matthews, G. R. Bigg, and D. P. Stevens, 2006: Interannual variability of the tropical Atlantic independent of and associated with ENSO: Part I. The north tropical Atlantic. Int. J. Climatol., 26, 1937-1956, https://doi.org/10.1002/ joc.1343.

Herrera, E., V. Magaña, and E. Caetano, 2015: Air-sea interactions and dynamical processes associated with the midsummer drought. Int. J. Climatol., 35, 1569-1578, https:// doi.org/10.1002/joc.4077.

Hidalgo, H. G., A. M. Durán-Quesada, J. A. Amador, and E. J. Alfaro, 2015: The Caribbean low-level jet, the inter-tropical convergence zone and precipitation patterns in the IntraAmericas Sea: A proposed dynamical mechanism. Geogr. Ann., 97A, 41-59, https://doi.org/10.1111/geoa.12085.

Huang, B., P. S. Schopf, and Z. Pan, 2002: The ENSO effect on the tropical Atlantic variability: A regionally coupled model study. Geophys. Res. Lett., 29, 2039, https://doi.org/10.1029/ 2002 GL014872.

Hurrell, J. W., Y. Kushnir, G. Ottersen, and M. Visbeck, 2003: An overview of the North Atlantic oscillation. The North Atlantic Oscillation: Climatic Significance and Environmental Impact, Geophys. Monogr., Vol. 134, Amer. Geophys. Union, 1-35, https://doi.org/10.1029/134GM01.

Kim, W., S. W. Yeh, J. H. Kim, J. S. Kug, and M. Kwon, 2011: The unique 2009-2010 El Niño event: A fast phase transition of warm pool El Niño to La Niña. Geophys. Res. Lett., 38, L15809, https://doi.org/10.1029/2011GL048521.

Klein, S. A., B. J. Soden, and N. C. Lau, 1999: Remote sea surface temperature variations during ENSO: Evidence for a tropical atmospheric bridge. J. Climate, 12, 917-932, https://doi.org/ 10.1175/1520-0442(1999)012<0917:RSSTVD>2.0.CO;2.

Lee, S. K., D. B. Enfield, and C. Wang, 2008: Why do some El Niños have no impact on tropical North Atlantic SST? Geophys. Res. Lett., 35, L16705, https://doi.org/10.1029/ 2008 GL034734.

Legeckis, R., 1988: Upwelling off the Gulfs of Panama and Papagayo in the tropical Pacific during March 1985. J. Geophys. Res., 93, 15 485-15 489, https://doi.org/10.1029/JC093iC12p15485.

Liang, J.-H., J. C. McWilliams, and N. Gruber, 2009: High-frequency response of the ocean to mountain gap winds in the northeastern tropical Pacific. J. Geophys. Res., 114, C12005, https://doi.org/10.1029/2009JC005370.

Liu, Y., S. K. Lee, D. B. Enfield, B. A. Muhling, J. T. Lamkin, F. E. Muller-Karger, and M. A. Roffer, 2015: Potential impact of climate change on the Intra-Americas Sea: Part-1. A dynamic downscaling of the CMIP5 model projections. J. Mar. Syst., 148, 56-69, https://doi.org/10.1016/j.jmarsys. 2015.01.007.

Magaña, V., and E. Caetano, 2005: Temporal evolution of summer convective activity over the Americas warm pools. Geophys. Res. Lett., 32, L02803, https://doi.org/10.1029/2004GL021033.

— J. A. Amador, and S. Medina, 1999: The midsummer drought over Mexico and Central America. J. Climate, 12, 1577-1588, https://doi.org/10.1175/1520-0442(1999)012<1577: TMDOMA $>2.0 . \mathrm{CO} ; 2$.

— Niño on precipitation in Mexico. Geofis. Int., 42, 313-330.

Maldonado, T., 2015: Aspects of climate variability during winter and summer in Central America. Ph.D. dissertation, Uppsala University, $60 \mathrm{pp}$.

— dicción climática estacional de eventos extremos y días con precipitación. Estudio de caso: Sur de América Central. Rev. InterSedes, 11, 182-214.

— extremos y días con precipitación sobre las vertientes Pacífico y Caribe de América Central, utilizando análisis de correlación canónica. Rev. InterSedes, 12, 78-108.

,,-- B. Fallas-López, and L. Alvarado, 2013: Seasonal prediction of extreme precipitation events and frequency of rainy days over Costa Rica, Central America, using canonical correlation analysis. Adv. Geosci., 33, 41-52, https://doi.org/ 10.5194/adgeo-33-41-2013.

- A. Rutgersson, J. Amador, E. Alfaro, and B. Claremar, 2016a: Variability of the Caribbean low-level jet during boreal winter: Large-scale forcings. Int. J. Climatol., 36, 1954-1969, https://doi.org/10.1002/joc.4472.

, — , E. Alfaro, J. Amador, and B. Claremar, 2016b: Interannual variability of the midsummer drought in Central 
America and the connection with sea surface temperatures. $A d v$. Geosci., 42, 35-50, https://doi.org/10.5194/adgeo-42-35-2016.

—, E. Alfaro, A. Rutgersson, and J. Amador, 2017: The early rainy season in Central America: The role of the tropical North Atlantic SSTs. Int. J. Climatol., 37, 3731-3742, https:// doi.org/10.1002/joc.4958.

Martin, E. R., and C. Schumacher, 2011: The Caribbean low-level jet and its relationship with precipitation in IPCC AR4 models. J. Climate, 24, 5935-5950, https://doi.org/10.1175/ JCLI-D-11-00134.1.

McGregor, S., A. Timmermann, N. Schneider, M. F. Stuecker, and M. H. England, 2012: The effect of the South Pacific convergence zone on the termination of El Niño events and the meridional asymmetry of ENSO. J. Climate, 25, 5566-5586, https://doi.org/10.1175/JCLI-D-11-00332.1.

Melice, J. L., and J. Servain, 2003: The tropical Atlantic meridional SST gradient index and its relationships with the SOI, NAO and Southern Ocean. Climate Dyn., 20, 447-464, https:// doi.org/10.1007/s00382-002-0289-x.

Mestas-Nuñez, A. M., D. B. Enfield, and C. Zhang, 2007: Water vapor fluxes over the Intra-Americas Sea: Seasonal and interannual variability and associations with rainfall. J. Climate, 20, 1910-1922, https://doi.org/10.1175/JCLI4096.1.

Muller-Karger, F. E., and Coauthors, 2015: Natural variability of surface oceanographic conditions in the offshore Gulf of Mexico. Prog. Oceanogr., 134, 54-76, https://doi.org/10.1016/ j.pocean.2014.12.007.

Muñoz, E., and D. Enfield, 2011: The boreal spring variability of the Intra-Americas low-level jet and its relation with precipitation and tornadoes in the eastern United States. Climate Dyn., 36, 247-259, https://doi.org/10.1007/s00382-009-0688-3.

- C. Wang, and D. Enfield, 2010: The Intra-Americas springtime sea surface temperature anomaly dipole as fingerprint of remote influences. J. Climate, 23, 43-56, https://doi.org/ 10.1175/2009JCLI3006.1.

Navarra, A., and V. Simoncini, 2010: A Guide to Empirical Orthogonal Functions for Climate Data Analysis. Springer Science and Business Media, $151 \mathrm{pp}$.

Paredes-Trejo, F. J., H. A. Barbosa, M. A. Peñaloza-Murillo, M. A. Moreno, and A. Farías, 2016: Intercomparison of improved satellite rainfall estimation with CHIRPS gridded product and rain gauge data over Venezuela. Atmósfera, 29, 323-342, https://doi.org/10.20937/ATM.2016.29.04.04.

Park, J. H., J. S. Kug, T. Li, and S. K. Behera, 2018: Predicting El Niño beyond 1-year lead: Effect of the Western Hemisphere warm pool. Sci. Rep., 8, 14 957, https://doi.org/10.1038/s41598018-33191-7.

Perdigón-Morales, J., R. Romero-Centeno, P. Ordóñez Pérez, and B. S. Barrett, 2018: The midsummer drought in Mexico: Perspectives on duration and intensity from the CHIRPS precipitation database. Int. J. Climatol., 38, 2174-2186, https:// doi.org/10.1002/joc.5322.

Philander, S. G. H., D. Gu, G. Lambert, T. Li, D. Halpern, N. C. Lau, and R. C. Pacanowski, 1996: Why the ITCZ is mostly north of the equator. J. Climate, 9, 2958-2972, https://doi.org/ 10.1175/1520-0442(1996)009<2958:WTIIMN>2.0.CO;2.

Poveda, G., P. R. Waylen, and R. S. Pulwarty, 2006: Annual and inter-annual variability of the present climate in northern South America and southern Mesoamerica. Palaeogeogr. Palaeoclimatol. Palaeoecol., 234, 3-27, https://doi.org/10.1016/ j.palaeo.2005.10.031.

Rauscher, S. A., F. Kucharski, and D. B. Enfield, 2011: The role of regional SST warming variations in the drying of Meso-
America in future climate projections. J. Climate, 24, 20032016, https://doi.org/10.1175/2010JCLI3536.1.

Reynolds, R. W., T. M. Smith, C. Liu, D. B. Chelton, K. S. Casey, and M. G. Schlax, 2007: Daily high-resolution-blended analyses for sea surface temperature. J. Climate, 20, 5473-5496, https://doi.org/10.1175/2007JCLI1824.1.

Romero-Centeno, R., J. Zavala-Hidalgo, A. Gallegos, and J. J. O'Brien, 2003: Isthmus of Tehuantepec wind climatology and ENSO signal. J. Climate, 16, 2628-2639, https://doi.org/ 10.1175/1520-0442(2003)016<2628:IOTWCA > 2.0.CO;2.

, - — , and G. B. Raga, 2007: Midsummer gap winds and lowlevel circulation over the eastern tropical Pacific. J. Climate, 20, 3768-3784, https://doi.org/10.1175/JCLI4220.1.

Rueda-Roa, D. T., and F. E. Muller-Karger, 2013: The southern Caribbean upwelling system: Sea surface temperature, wind forcing and chlorophyll concentration patterns. Deep-Sea Res. I, 78, https://doi.org/10.1016/j.dsr.2013.04.008.

Ruiz-Barradas, A., J. A. Carton, and S. Nigam, 2000: Structure of interannual-to-decadal climate variability in the tropical Atlantic sector. J. Climate, 13, 3285-3297, https://doi.org/10.1175/ 1520-0442(2000)013<3285:SOITDC $>2.0$. CO;2.

Saha, S., and Coauthors, 2010: The NCEP Climate Forecast System Reanalysis. Bull. Amer. Meteor. Soc., 91, 1015-1057, https:// doi.org/10.1175/2010BAMS3001.1.

, and Coauthors, 2014: The NCEP Climate Forecast System version 2. J. Climate, 27, 2185-2208, https://doi.org/10.1175/ JCLI-D-12-00823.1.

Salby, M. L., 1996: Fundamentals of Atmospheric Physics. Vol. 61, Academic Press, $627 \mathrm{pp}$.

Servain, J., and D. M. Legler, 1986: Empirical orthogonal function analyses of tropical Atlantic sea surface temperature and wind stress: 1964-1979. J. Geophys. Res., 91, 14 181-14191, https:// doi.org/10.1029/JC091iC12p14181.

Spence, J. M., M. A. Taylor, and A. A. Chen, 2004: The effect of concurrent sea-surface temperature anomalies in the tropical Pacific and Atlantic on Caribbean rainfall. Int. J. Climatol., 24, 1531-1541, https://doi.org/10.1002/joc.1068.

Stumpf, H. G., 1975: Satellite detection of upwelling in the Gulf of Tehuantepec, Mexico. J. Phys. Oceanogr., 5, 383-388, https:// doi.org/10.1175/1520-0485(1975)005<0383:SDOUIT>2.0.CO;2.

Sutton, R. T., W. A. Norton, and S. P. Jewson, 2000: The North Atlantic Oscillation-What role for the ocean? Atmos. Sci. Lett., 1, 89-100, https://doi.org/10.1006/asle.2000.0018.

Taylor, M. A., D. B. Enfield, and A. A. Chen, 2002: Influence of the tropical Atlantic versus the tropical Pacific on Caribbean rainfall. J. Geophys. Res., 107, 3127, https://doi.org/10.1029/ 2001JC001097.

Vázquez-Aguirre, J. L., 2007: Variabilidad de la precipitación en la República Mexicana, M.S. Thesis, Centro de Ciencias de la Atmósfera, Universidad Nacional Autónoma de México, 110 pp.

Verdin, A., C. Funk, B. Rajagopalan, and W. Kleiber, 2016: Kriging and local polynomial methods for blending satellitederived and gauge precipitation estimates to support hydrologic early warning systems. IEEE Trans. Geosci. Remote Sens., 54, 2552-2562, https://doi.org/10.1109/TGRS.2015. 2502956.

Von Storch, H., and F. W. Zwiers, 2002: Statistical Analysis in Climate Research. Cambridge University Press, 495 pp.

Wallace, J. M., and D. S. Gutzler, 1981: Teleconnections in the geopotential height field during the Northern Hemisphere winter. Mon. Wea. Rev., 109, 784-812, https://doi.org/10.1175/ 1520-0493(1981)109<0784:TITGHF>2.0.CO;2. 
C. Smith, and C. S. Bretherton, 1992: Singular value decomposition of wintertime sea surface temperature and 500mb height anomalies. J. Climate, 5, 561-576, https://doi.org/ 10.1175/1520-0442(1992)005<0561:SVDOWS >2.0.CO;2.

Wang, C., 2004: ENSO, Atlantic climate variability, and the Walker and Hadley circulations. The Hadley Circulation: Present, Past, and Future, Springer, 173-202.

- 2007: Variability of the Caribbean low-level jet and its relations to climate. Climate Dyn., 29, 411-422, https://doi.org/ 10.1007/s00382-007-0243-z.

— warm pool. Geophys. Res. Lett., 28, 1635-1638, https://doi.org/ 10.1029/2000GL011763.

, S. K. Lee, and D. B. Enfield, 2008: Climate response to anomalously large and small Atlantic warm pools during the summer. J. Climate, 21, 2437-2450, https://doi.org/10.1175/2007JCLI2029.1.
Waylen, P. R., C. N. Caviedes, and M. E. Quesada, 1996: Interannual variability of monthly precipitation in Costa Rica. J. Climate, 9, 2606-2613, https://doi.org/10.1175/1520-0442(1996) 009<2606:IVOMPI >2.0.CO;2.

Whyte, F. S., M. A. Taylor, T. S. Stephenson, and J. D. Campbell, 2008: Features of the Caribbean low level jet. Int. J. Climatol., 28, 119-128, https://doi.org/10.1002/joc.1510.

Wilks, D. S., 2006: Statistical Methods in the Atmospheric Sciences. 2nd ed. International Geophysics Series, $627 \mathrm{pp}$.

Zárate-Hernández, E., 2013: Climatología de masas invernales de aire frío que alcanzan Centroamérica y el Caribe y su relación con algunos índices árticos. Top. Meteor. Oceanogr., 12, 35-55.

Zavala-Hidalgo, J., A. Parés-Sierra, and J. Ochoa, 2002: Seasonal variability of the temperature and heat fluxes in the Gulf of Mexico. Atmósfera, 15, 81-104. 